\title{
Dendrocalamus strictus ((Roxb.) Nees): A Suitable Host for the Maintenance and Propagation of AM Fungi under Temperate Conditions
}

\author{
Shipra Singh, ${ }^{1}$ Ajay Kumar, ${ }^{1,2}$ Anita Pandey, ${ }^{1}$ and Lok Man S. Palni ${ }^{1}$ \\ ${ }^{1}$ Biotechnological Applications, GB Pant Institute of Himalayan Environment and Development, Kosi-Katarmal, \\ Almora 263 643, Uttarakhand, India \\ ${ }^{2}$ Technico Agri-Sciences Limited, Sector 9-C, Chandigarh 160 009, India
}

Correspondence should be addressed to Anita Pandey, anita@gbpihed.nic.in

Received 21 December 2011; Accepted 16 February 2012

Academic Editor: H. Heuer

Copyright ( 2012 Shipra Singh et al. This is an open access article distributed under the Creative Commons Attribution License, which permits unrestricted use, distribution, and reproduction in any medium, provided the original work is properly cited.

\begin{abstract}
Dendrocalamus strictus ((Roxb.) Nees) was tested as a perennial host plant for propagation of an arbuscular mycorrhizal (AM) fungal consortium, initially isolated from rhizosphere of tea plants growing in the colder regions. The host performance in terms of colonization and spore production was compared with two annual hosts. The mycorrhizal dependency and growth enhancement potential were analyzed to test the suitability of $D$. strictus as a host plant. After 90 days of growth, $77.2 \%$ roots of D. strictus were found to be colonized by AM fungi with a spore count of 7 per g soil. AM fungal colonization and spore density values were lower in case of the host plants tested. Growth of D. strictus plants was found to be enhanced, in terms of all studied parameters; significant increases were recorded in shoot length as well as fresh and dry weight of shoots, a part of commercial importance. Similarly, P content, protein concentration, chlorophyll a and chlorophyll b contents were found to increase significantly. These data suggest that $D$. strictus can be used for the multiplication of AM fungi, isolated originally from the rhizosphere of tea; simultaneously, higher shoot biomass can provide additional economic benefit, using this environment friendly technology.
\end{abstract}

\section{Introduction}

Arbuscular mycorrhizal (AM) fungi form a major component of the soil microbiota in natural ecosystems and play an important role in the mineralization and plant nutrient cycling. In a symbiotic association with AM fungi, the host plants benefit through increased efficiency of nutrients and absorption of water, that is reflected in overall enhanced plant growth. Positive effects of this association are also seen in terms of increased stress tolerance [1]. In spite of potential for use in agriculture and forestry, AM fungi have received little attention due to their obligate symbiotic nature, that is, it is not possible to culture these on synthetic media, unlike other plant growth promoting microorganisms (e.g., rhizobia and pseudomonads, etc.).

The understanding of physiological, biochemical, and genetic characteristics of AM fungi as well as their practical exploitation is constrained on account of inability to culture under in vitro conditions. Therefore, the AM fungi are grown on a suitable living host root system. The potential utilization of AM fungi greatly depends on the ability to produce suitable inoculum using a simple and inexpensive methodology; the inoculum should be such that it can be spread easily on agricultural fields with traditional farm equipments. AM fungi are generally propagated easily using a pot-culture technique. Fungal inocula, usually made of spores and colonized root segments, are mixed with a suitable substrate; the colonized substrate as well as root segments can be used as AM inoculum.

An important criterion in the selection of a host plant is its mycorrhizal potential (i.e., its capacity to be colonized by the AM fungi and to promote their growth and sporulation); tolerance to growth under growth chamber and greenhouse conditions, and an extensive root system comprising of solid but nonlignified roots are other considerations. Leek (Allium porrum L.), sudan grass (Sorghum bicolor (L.) Moench), corn 
(Zea mays L.), and bahia grass (Paspalum notatum Flugge) are frequently used as plant hosts for inoculum production [2].

Bamboo and tea, both are economically important and perennial crops grown worldwide under tropical to temperate climatic conditions $[3,4]$. In a recent study, rhizosphere associates of tea including the AM fungi, growing under temperate climate, have been investigated leading to the development of a soil-based AM fungal consortium for field applications [5-7]. The host plants tested so far (such as sorghum, barley, and clover) to mass propagate AM fungi, in a short duration, also have short life cycles. This almost invariably means that the aerial parts (often of commercial value) of the host plant are discarded. Furthermore, a second host plant (sometimes other species) is needed to continue propagation over longer periods. To overcome these problems, the present study was undertaken to test Dendrocalamus strictus (Roxb. Nees; common name: lathi baans-bamboo) as a perennial host plant for the propagation of AM fungi of colder regions. D. strictus, an evergreen, fast growing, multiutility bamboo, performs well under tropical, subtropical, and temperate conditions. It has been used to propagate AM fungi, such as those associated with tea plants growing in the mountain regions. Comparisons were also made for the colonizing efficiency and sporulation with two annual host plants, Zea mays L. and Eleusine coracana L.

\section{Materials and Methods}

2.1. Seed Collection and Preparation of the AM Fungal Inoculum. Seeds of D. strictus were obtained from Kumaun nursery, Ramnagar, District Nainital. Previously prepared indigenous AM fungal consortium, containing native populations from the natural tea rhizosphere [5-7], was used as inoculum.

2.2. Pot Culture for AM Fungi. Seeds of $Z$. mays, E. coracana, and D. strictus were surface sterilized with $\mathrm{HgCl}_{2}(0.01 \%$, $\left.\mathrm{wv}^{-1}, 2 \mathrm{~min}\right)$, and washed with sterile distilled water $(\times 3)$, and then sown in earthen pots $(30 \mathrm{~cm} \mathrm{ht} \times 25 \mathrm{~cm}$ dia $)$ filled with sterilized soil-sand mixture $(1: 1, \mathrm{v} / \mathrm{v}$; autoclaved at $121^{\circ} \mathrm{C}, 1.1 \mathrm{Kg} \mathrm{cm}^{-2}$ for $\left.1 \mathrm{~h} \times 3\right)$. Soil-based AM fungal consortium (10 g soil per seed), containing 20-30 AM fungal spores and root fragments, used as inoculum and was placed below the seed at the time of sowing. Control pots were left uninoculated. All pots were kept in the greenhouse (incident sunlight $1 / 3$ rd of ambient) and watered every alternate day with tap water. The analyses of AM fungal colonization and spore densities in respect of all the three host plants ( $Z$. mays, E. coracana, and D. strictus) were carried out after 45 and 90 days following inoculation. To elucidate the effect of AM fungal inoculation on the growth of D. strictus, plants were harvested after 6 months of growth to record observations.

2.3. AM Fungal Colonization. The roots of inoculated and uninoculated (control) plants were rinsed with tap water and cut into $1 \mathrm{~cm}$ pieces for staining with trypan blue [8]. One hundred root segments were randomly picked and mounted on glass slides in lactophenol for microscopic examination
(Nikon, Optiphot-2). The colonization was calculated using the following formula:

$\%$ colonization

$$
=\frac{\text { Total no. of root segments colonized }}{\text { Total no. of root segments examined }} \times 100 \text {. }
$$

2.4. Spore Density. Spores were isolated by wet sieving and decanting [9] and counted on filter paper discs [10]. The identifications were done as reported earlier $[5,6]$. Spores, spore clusters, and sporocarps, obtained from all the sieves, were observed by using a stereo-zoom microscope. Thereafter, spores looking similar in size and colour were separated from the spore mixture and later identified with compound microscope. Identifications were based on current descriptions and identification manuals [11, http://invam.caf.wvu .edu/fungi/Taxonomy/speciesID.htm].

2.5. Growth Parameters. D. strictus plants were gently uprooted 6 months after seed sowing and washed thoroughly in tap water to remove soil particles from the surface of roots; these were then blotted dry. The growth parameters were measured in terms of root and shoot length, fresh weight, dry weight, and the number of tillers. Dry weight was determined after drying to constant weight at $60^{\circ} \mathrm{C}$. Root: shoot ratio was calculated in terms of dry weight. Protein and chlorophyll content were determined spectrophotometrically according to Lowry et al. [12] and Dere et al. [13], respectively. The $\mathrm{P}$ content of plants was analyzed colorimetrically using the vanadomolybdate method [14].

2.6. Mycorrhizal Dependency. The growth response of mycorrhizal plants (MP) versus nonmycorrhizal plants (NMP) was estimated by calculating mycorrhizal dependency (MD) of the host plants according to Plenchette et al. [15]. For both the hosts, the mycorrhizal dependency was calculated expressing the difference between the dry shoot mass of MP and dry shoot mass of NMP as a percentage of dry shoot mass of MP:

$$
\begin{aligned}
\mathrm{MD}= & \frac{\text { Dry shoot mass of MP }- \text { Dry shoot mass of NMP }}{\text { Dry shoot mass of MP }} \\
& \times 100 .
\end{aligned}
$$

2.7. Statistical Analysis. One-way analysis of variance (ANOVA) was performed to enumerate significant differences between the treatments. Correlation study was performed by the use of excel programme of Windows Microsoft Corp, and the significance of correlation was analyzed by Student's $t$-test according to Gurumani [16].

\section{Results}

3.1. AM Colonization and Spore Counts. While all the three host plants ( $Z$. mays, E. coracana, and D. strictus) tested were useful for the propagation of AM fungi isolated from the rhizosphere of tea, their effectiveness varied. Colonization 


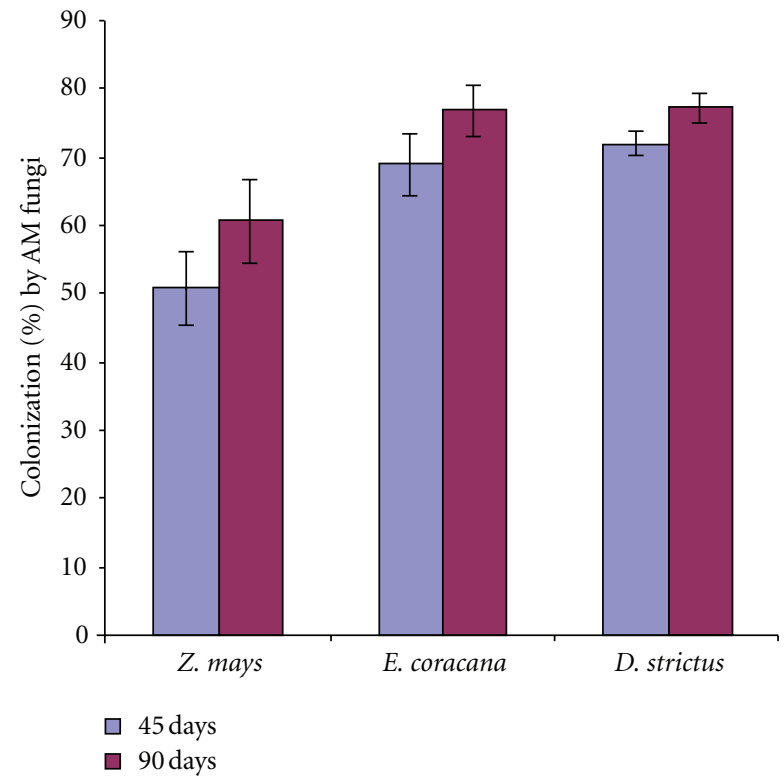

(a)

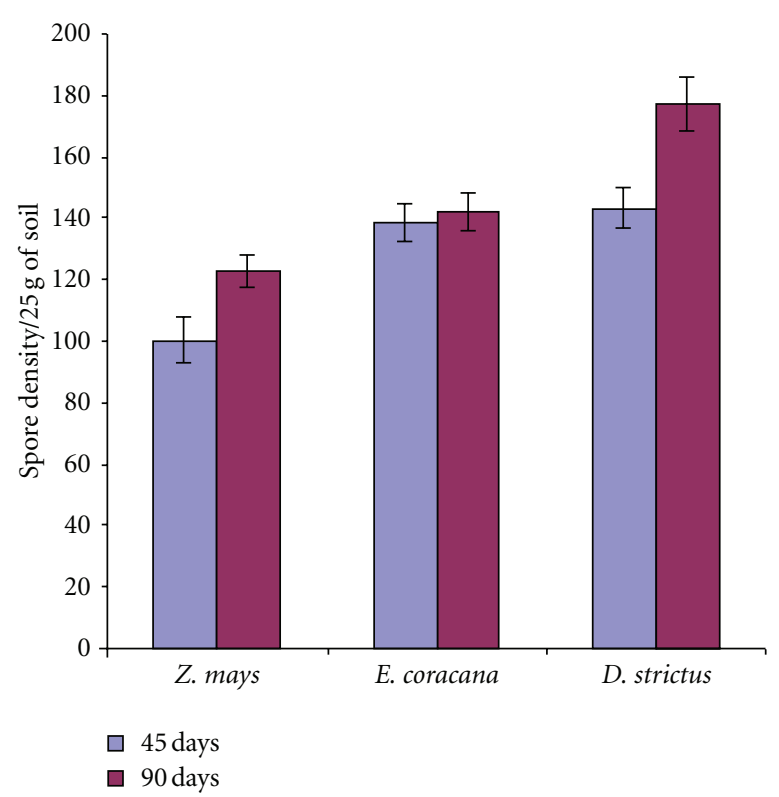

(b)

Figure 1: Colonization by AM fungi (a) and the spore density (b) in Zea mays, Eleusine coracana, and Dendrocalamus strictus after 45 and 90 days of inoculation. Bars show standard error.

TABLE 1: Effect of AM fungal inoculation on the growth of Dendrocalamus strictus plants, after 6 months of inoculation.

\begin{tabular}{lccc}
\hline Parameter & Control & AM inoculated & $P$ value (ANOVA) \\
\hline Root length $(\mathrm{cm})$ & $28.6 \pm 4.3$ & $31.4 \pm 5.1$ & 0.206 \\
Root fresh weight $(\mathrm{g})$ & $10.7 \pm 6.8$ & $19.4 \pm 7.1$ & 0.012 \\
Root dry weight $(\mathrm{g})$ & $3.7 \pm 3.2$ & $6.1 \pm 2.0$ & 0.06 \\
Shoot length $(\mathrm{cm})$ & $108.9 \pm 15.7$ & $135.5 \pm 13.4$ & 0.0007 \\
Shoot fresh weight $(\mathrm{g})$ & $15.0 \pm 5.9$ & $59.3 \pm 12.0$ & $<0.0001$ \\
Shoot dry weight $(\mathrm{g})$ & $9.7 \pm 3.9$ & $40.5 \pm 11.4$ & $<0.0001$ \\
Root: shoot & $0.34 \pm 0.1$ & $0.15 \pm 0.0$ & 0.0004 \\
Tiller numbers & $3.8 \pm 1.0$ & $5.6 \pm 1.9$ & 0.016 \\
\hline
\end{tabular}

Values represent mean \pm standard deviation; $n=10$.

and data on spore density during establishment of trap cultures have been presented in Figures 1(a) and 1(b), respectively. Higher colonization (77.2\%) and spore density (172 $25 \mathrm{~g}^{-1}$ soil) were recorded in D. strictus compared to both the annuals (Z. mays; $50.8 \%$ and 122 , and E. coracana; $76.8 \%$ and 142 , resp.) after 90 days of inoculation. Soil-based inoculum from the tea rhizosphere could result in significantly higher colonization in D. strictus and E. coracana in comparison to $Z$. mays. Similarly, the spore density was also significantly higher in $D$. strictus after 45 as well as 90 days of inoculation than what were recorded in respect of $Z$. mays and E. coracana; significantly higher values were recorded in E. coracana over those found for $Z$. mays.

A total of 19 AM fungal morphotypes, that included 16 morphotypes of Glomus and 3 of Acaulospora, were propagated from the tea rhizosphere using $D$. strictus; these were similar to earlier observations recorded for the other two host plants (Z. mays and E. coracana [6]).
3.2. Effect of AM Inoculation on Growth. Enhanced growth was observed in the inoculated plants of D. strictus over uninoculated controls (Table 1). Values in respect of all the parameters recorded in this study were higher in treated plants over the respective values in untreated controls; the increase was, however, not significant for all the parameters. Inoculation with AM fungi resulted in 9.8 and $24.4 \%$ increase in root and shoot length, respectively, over control. Significant values ( $P \leq 0.05$; one-way ANOVA) of 80 and $294 \%$ increase, over uninoculated plants, were recorded in root and shoot fresh weight, respectively, of treated plants. Significant increase in root and shoot dry weight (64 and $315 \%$, resp., over control) was also recorded. A decrease in root: shoot ratio (55\%; dry weight basis) was recorded in D. strictus plants treated with AM fungi. Number of tillers was found to increase by $47 \%$ in treated plants. The overall mycorrhizal dependency for D. strictus plants was found to be $72.55 \pm 1.37 \%$. 
TABLe 2: Effect of AM fungal inoculation on chlorophyll, protein, and P contents of Dendrocalamus strictus plants, after 6 months of inoculation.

\begin{tabular}{lccc}
\hline Parameter & Control & AM inoculated & $P$ value $($ ANOVA) \\
\hline Chlorophyll a $\left(\mathrm{mg} \mathrm{g}^{-1}\right)$ & $1.30 \pm 0.26$ & $2.77 \pm 0.34$ & $<0.0001$ \\
Chlorophyll b $\left(\mathrm{mg} \mathrm{g}^{-1}\right)$ & $1.29 \pm 0.29$ & $1.59 \pm 0.33$ & 0.13 \\
Total chlorophyll $\left(\mathrm{mg} \mathrm{g}^{-1}\right)$ & $2.59 \pm 0.52$ & $4.29 \pm 0.66$ & $<0.0001$ \\
Protein $\left(\mathrm{mg} \mathrm{g}^{-1}\right)$ & $0.66 \pm 0.02$ & $0.86 \pm 0.03$ & $<0.0001$ \\
Phosphorus $(\%)$ & $0.04 \pm 0.01$ & $0.06 \pm 0.01$ & $<0.0001$ \\
\hline
\end{tabular}

Values represent mean \pm standard deviation; $n=10$.

TABLE 3: Correlation observed between various growth parameters and \% AM colonization/mycorrhizal dependency; the analyses were carried out using the Student's $t$-test.

\begin{tabular}{|c|c|c|c|c|c|c|}
\hline & \multicolumn{3}{|c|}{$\begin{array}{c}\text { Significance of correlations with mycorrhizal } \\
\text { dependency }\end{array}$} & \multicolumn{3}{|c|}{$\begin{array}{l}\text { Significance of correlations with \% AM } \\
\text { colonization }\end{array}$} \\
\hline & $r$-value & SE & $t$-value & $r$-value & SE & $t$-value \\
\hline Root length & 0.96 & 0.03 & 27.83 & 0.95 & 0.03 & 26.31 \\
\hline Root fresh weight & 0.92 & 0.05 & 18.56 & 0.90 & 0.05 & 17.04 \\
\hline Root dry weight & 0.86 & 0.06 & 13.90 & 0.85 & 0.06 & 13.08 \\
\hline Shoot length & 0.93 & 0.04 & 21.38 & 0.92 & 0.05 & 18.84 \\
\hline Shoot fresh weight & 0.97 & 0.02 & 36.64 & 0.97 & 0.03 & 32.35 \\
\hline Shoot dry weight & 0.97 & 0.02 & 36.52 & 0.96 & 0.03 & 30.71 \\
\hline Root: shoot & -0.19 & 0.12 & -1.55 & -0.21 & 0.12 & -1.77 \\
\hline Tiller numbers & 0.87 & 0.06 & 14.63 & 0.84 & 0.06 & 12.71 \\
\hline Chlorophyll a & 0.95 & 0.04 & 23.98 & 0.92 & 0.05 & 18.54 \\
\hline Chlorophyll b & 0.95 & 0.03 & 25.85 & 0.95 & 0.03 & 25.26 \\
\hline Total chlorophyll & 0.96 & 0.03 & 29.43 & 0.95 & 0.04 & 23.96 \\
\hline Protein & 0.33 & 0.12 & 2.87 & 0.38 & 0.11 & 3.31 \\
\hline Phosphorus & 0.93 & 0.04 & 20.09 & 0.91 & 0.05 & 18.34 \\
\hline
\end{tabular}

SE: standard error.

The effect of AM inoculation on chlorophyll, protein, and $\mathrm{P}$ contents was also found to be positive in D. strictus plants (Table 2). The increase was highly significant $(P \leq$ 0.001 ; one-way ANOVA) in respect of all these parameters, except for chlorophyll $b$, in inoculated plants over control. Correlation analysis revealed positive relationship between $\%$ AM colonization/mycorrhizal dependency and the various growth parameters, except root: shoot ratio (Table 3 ).

\section{Discussion}

D. strictus, a perennial host, and two annual host plants $(Z$. mays and E. coracana) were used in the present study for the "trap culture" establishment. The three host plants used in this study are known to have fast growth cycle and extensive, nonlignified root system. In an earlier study, AM fungal consortia were prepared from the cultivated as well as natural tea rhizosphere using E. coracana as host; however, a second host (wheat) was required to continue the propagation cycle [6] during winter. D. strictus, being a perennial host, does not require a second host to continue the propagation cycle. Furthermore, the above-ground biomass can be removed from time to time for commercial use; this species is well known for its social and economic relevance. The young culms are exploited, in some bamboo species, as a source of food and wood for furniture, handicraft items, for making houses and packing boxes, and so forth.

The substrate used in the study consisted of autoclaved soil: sand (1:1) mixture; the sand was mixed with soil to increase aeration. Pasteurized, steamed, or irradiated growing substrates are required in order to avoid culture contamination which could affect the inoculum quality. A wellaerated substrate, such as the coarse textured sandy soil, has been recommended earlier [17].

The AM fungal colonization and subsequent spore production depend on the type of host as well as the duration of infection of these symbiotic organisms. Generally, with increase in the period of growth after infection, the host root colonization increases, with little effect on spore production. It is the host type, which is more important for spore production $[18,19]$. This may be the reason for observed higher colonization and spore count in case of $D$. strictus, compared to two annual hosts.

Results of an earlier experiment for mass production of AM inoculum using selected host plants indicated a gradual but concomitant increase in terms of both the root colonization and spore numbers, produced with increase in the period of growth. Significantly higher spore formation 
was recorded in D. strictus after 45 and 90 days; this clearly indicated its suitability as an appropriate host for producing AM inoculum. Therefore, soil from around the base of $D$. strictus plants can be used as inoculum, and the plant can be used as a suitable host for mass propagation of pure cultures of AM fungi, originally isolated from the rhizosphere of tea plants. Based on the data for colonization and spore counts, E. coracana can be considered as the second best host, while $Z$. mays would appear to be the least efficient host for the purpose of mass propagation of AM fungi.

This study demonstrated the effectiveness of AM fungal consortium developed from the rhizosphere of tea in terms of promoting the growth of $D$. strictus plants as per recorded parameters. AM fungal inoculations have been reported to improve both above ground as well as below ground biomass in different plant species $[20,21]$. Similar effect has been observed in different bamboo species, including D. strictus, grown under tropical conditions $[22,23]$. However, reports are not available under temperate conditions. Inoculation with a consortium of AM fungi is often associated with additional and consistent benefits to the plants in comparison to inoculations with a single species [24]. Growth stimulating effects of indigenously developed consortial inocula have been reported earlier [25]. The consortium used in this study has earlier been shown to improve the growth of maize and wheat plants [6]. The high Mycorrhizal dependency may have resulted in increased growth of $D$. strictus plants observed in this investigation; this was supported by a significant positive correlation recorded between mycorrhizal dependency and studied growth parameters, including the biochemical indicators (e.g., nutritional and chlorophyll contents). Mycorrhizal dependency is an important parameter to elucidate growth response of mycorrhizal plants compared to their nonmycorrhizal counterparts [15].

In conclusion, the present study shows that $D$. strictus can be used to suitably multiply AM fungi, originally from the rhizosphere of tea plants growing in the colder regions, without the need of additional host(s) to continue the propagation cycle, a limitation frequently encountered when annuals are used as host plants. Further, the aerial parts (shoots) can also be removed from time to time for additional economic benefit. $D$. strictus being a major forest species, with large geographical coverage, can also be used for afforestation purposes, while using AM fungal consortia as bioinoculant.

\section{Acknowledgments}

The Departments of Biotechnology and Science and Technology (Science and Society Division), New Delhi, Government of India, are acknowledged for financial support.

\section{References}

[1] S. E. Smith and D. J. Read, Mycorrhizal Symbiosis, Academic Press, Cambridge, UK, 1997.

[2] J. E. Struble and H. D. Skipper, "Vesicular-arbuscular mycorrhizal fungal spore production as influenced by plant species," Plant and Soil, vol. 109, no. 2, pp. 277-280, 1988.
[3] Anonymous, Bamboo Forest News for Asia and Pacific, Food and Agriculture Organization, Bangkok Thailand, 1978.

[4] A. Pandey and L. M. S. Palni, "Tea rhizosphere: microbial diversity and characteristic features and comments on microbial communication in rhizosphere," International Journal of Tea Science, vol. 3, no. 3-4, pp. 285-290, 2004.

[5] S. Singh, A. Pandey, B. Chaurasia, and L. M. S. Palni, "Diversity of arbuscular mycorrhizal fungi associated with the rhizosphere of tea growing in 'natural' and 'cultivated' ecosites," Biology and Fertility of Soils, vol. 44, no. 3, pp. 491-500, 2008.

[6] S. Singh, A. Pandey, and L. M. S. Palni, "Screening of arbuscular mycorrhizal fungal consortia developed from the rhizospheres of natural and cultivated tea plants for growth promotion in tea [Camellia sinensis (L.) O. Kuntze]," Pedobiologia, vol. 52, no. 2, pp. 119-125, 2008.

[7] S. Singh, A. Pandey, B. Kumar, and L. M. S. Palni, "Enhancement in growth and quality parameters of tea [Camellia sinensis (L.) O. Kuntze] through inoculation with arbuscular mycorrhizal fungi in an acid soil," Biology and Fertility of Soils, vol. 46, no. 5, pp. 427-433, 2010.

[8] J. M. Phillips and D. S. Hayman, "Improved procedure for clearing roots and staining parasitic and vesicular arbuscular mycorrhizal fungi for rapid assessment of infections," Transactions of the British Mycological Society, vol. 55, no. 1, pp. 158$161,1970$.

[9] J. W. Gerdemann and T. H. Nicolson, "Spores of mycorrhizal endogone species extracted from soil by wet sieving and decanting," Transactions of the British Mycological Society, vol. 46, no. 2, pp. 235-244, 1963.

[10] A. Gaur and A. Adholeya, "Estimation of AMF spores in soil: a modified method," Mycorrhiza News, vol. 6, pp. 10-11, 1994.

[11] N. C. Schenck and Y. Perez, Manual for the Identification of VA Mycorrhizal Fungi, Synergistic Publications, Gainesville, Fla, USA, 3rd edition, 1990.

[12] O. H. Lowry, N. J. Rosenbrough, A. L. Farr, and R. J. Randall, "Protein measurement with the folin phenol reagent," The Journal of Biological Chemistry, vol. 193, no. 1, pp. 265-275, 1951.

[13] S. Dere, T. Gunes, and R. Sivaci, "Spectrophotometric determination of chlorophyll a, b and total carotenoide contents of some algae species using different solvents," Turkish Journal of Botany, vol. 22, pp. 13-17, 1998.

[14] S. E. Allen, Chemical Analysis of Ecological Materials, Blackwell Scientific, London, UK, 2nd edition, 1974.

[15] C. Plenchette, J. A. Fortin, and V. Furlan, "Growth responses of several plant species to mycorrhizae in a soil of moderate P-fertility. I. Mycorrhizal dependency under field conditions," Plant and Soil, vol. 70, no. 2, pp. 199-209, 1983.

[16] N. Gurumani, An Introduction to Biostatistics, MJP Publishers, Chennai, India, 2005.

[17] A. Gaur and A. Adholeya, "Effects of the particle size of soil-less substrates upon AM fungus inoculum production," Mycorrhiza, vol. 10, no. 1, pp. 43-48, 2000.

[18] J. D. Bever, J. B. Morton, J. Antonovics, and P. A. Schultz, "Host-dependent sporulation and species diversity of arbuscular mycorrhizal fungi in a mown grassland," Journal of Ecology, vol. 84, no. 1, pp. 71-82, 1996.

[19] A. H. Eom, D. C. Hartnett, and G. W. T. Wilson, "Host plant species effects on arbuscular mycorrhizal fungal communities in tallgrass prairie," Oecologia, vol. 122, no. 3, pp. 435-444, 2000.

[20] M. L. Gupta and K. K. Janardhanan, "Mycorrhizal association of Glomus aggregatum with palmarosa enhances growth and biomass," Plant and Soil, vol. 131, no. 2, pp. 261-263, 1991. 
[21] S. V. Silveira, R. Lorscheiter, I. B. I. Barros, S. F. Schwarz, and P. V. D. Souza, "Mentha piperita as a multiplying of arbuscular mycorrhizal fungi," Revista Brasileira de Medicina, vol. 8, pp. 91-97, 2006.

[22] R. Ravikumar, G. Ananthakrishnan, T. Appasamy, and A. Ganapathi, "Effect of endomycorrhizae (VAM) on bamboo seedling growth and biomass productivity," Forest Ecology and Management, vol. 98, no. 3, pp. 205-208, 1997.

[23] T. Muthukumar and K. Udaiyan, "Growth of nursery-grown bamboo inoculated with arbuscular mycorrhizal fungi and plant growth promoting rhizobacteria in two tropical soil types with and without fertilizer application," New Forests, vol. 31, no. 3, pp. 469-485, 2006.

[24] I. Koomen, C. Grace, and D. S. Hayman, "Effectiveness of single and multiple mycorrhizal inocula on growth of clover and strawberry plants at two soil pHs," Soil Biology and Biochemistry, vol. 19, no. 5, pp. 539-544, 1987.

[25] A. Gaur and A. Adholeya, "Mycorrhizal effects on the acclimatization, survival, growth and chlorophyll of micropropagated Syngonium and Draceana inoculated at weaning and hardening stages," Mycorrhiza, vol. 9, no. 4, pp. 215-219, 1999. 

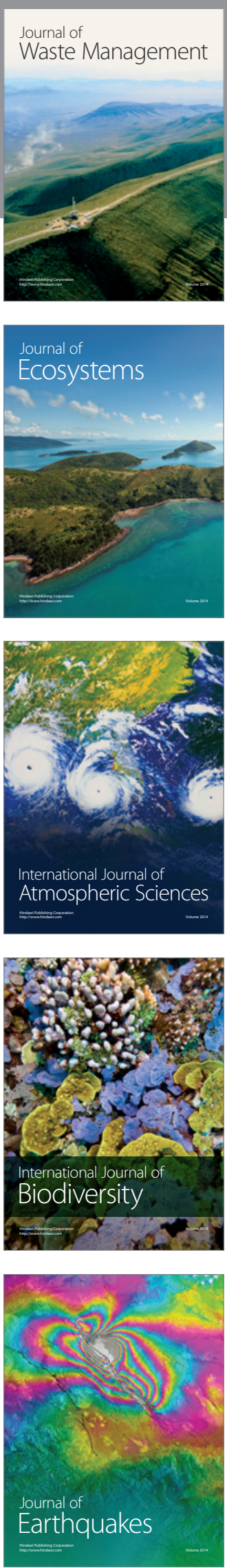
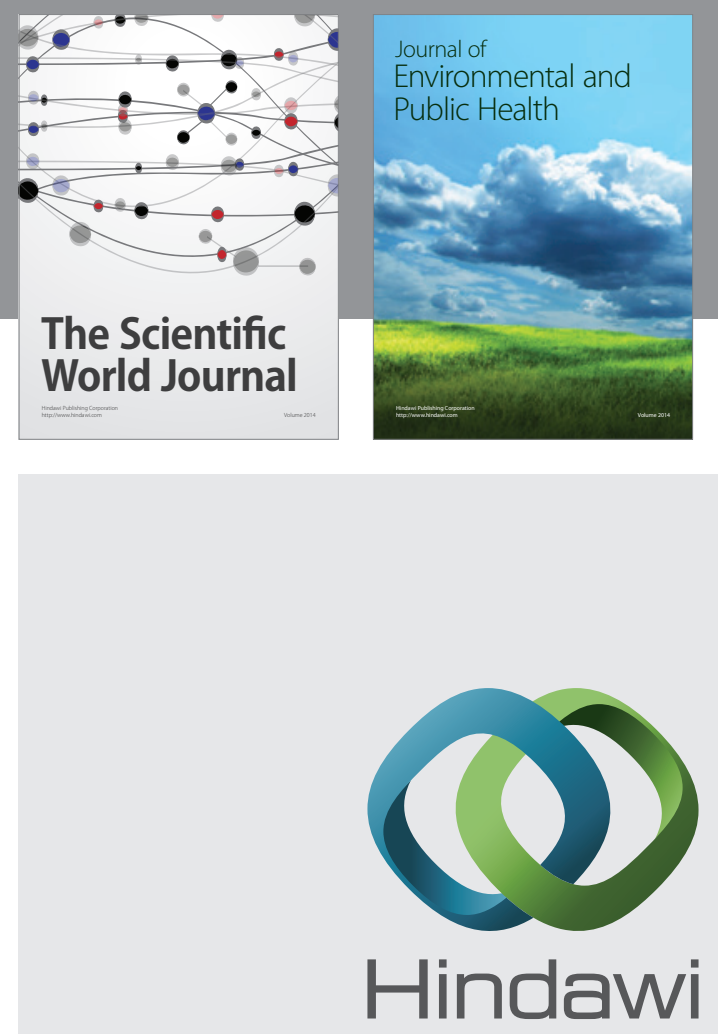

Submit your manuscripts at

http://www.hindawi.com
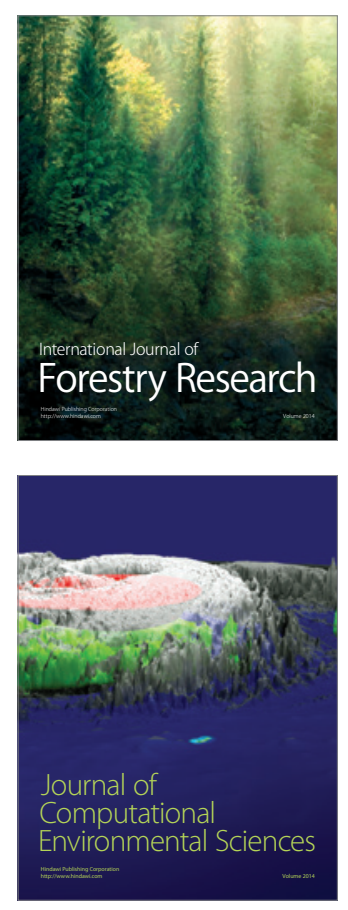
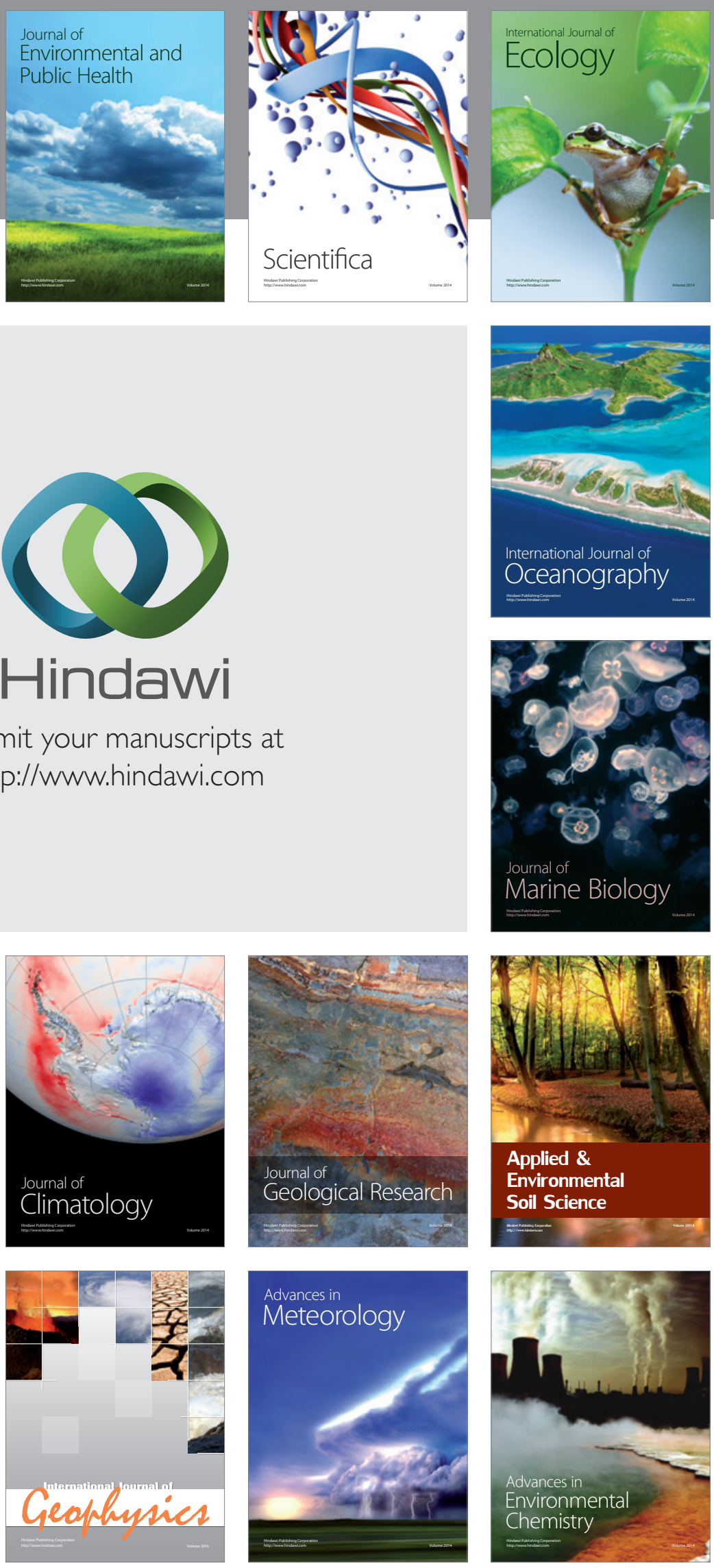